\title{
Personalidade e conduta violenta
}

\author{
Gabriel Chittó Gauer ${ }^{l}$
}

\section{Introdução}

A violência pode ser entendida como uma falha do comportamento humano em respeitar os limites entre a agressão aceitável e a inaceitável. A gênese da conduta violenta é multifatorial e ainda não se encontra completamente elucidada. Os estudos estatísticos e epidemiológicos nos auxiliam a delimitar o problema e avaliar o grau com que afeta os indivíduos e a sociedade. Dados do estudo Epidemiological Catchment Area (Swanson et al. 1990), nos Estados Unidos da América, sugerem que $3,7 \%$ da população comete um ou mais atos de violência a cada ano, e a incidência de comportamento agressivo durante toda vida é de aproximadamente $24 \%$ (Bland 1986). Ainda que as autoridades daquele país relatem uma diminuição nas taxas de criminalidade, em 1996 ocorreram 19.645 assassinatos, 95.769 estupros, e 537.050 roubos, contribuindo para um total de aproximadamente 500 milhões de dólares em bens subtraídos (Federal Bureau of Investigation 1996).

Nos EUA, uma mulher é sexualmente atacada a cada 45 segundos. Mais do que um terço dos americanos relatam terem assistido um homem espancar sua esposa ou namorada. Entre 1986 e 1993, o número de crianças abusadas ou negligenciadas dobrou e as seriamente feridas quadruplicou. Os assassinatos constituem-se numa importante forma de violência em locais de trabalho e é a forma de crime que

1Médico psiquiatra, doutor em clínica médica pela Pucrs, fez pós-doutorado no Maryland Center for anxiety Disorders, na Universidade de Maryland, EUA; professor do Depto. de Psiquiatria e Medicina Legal da Famed e do Programa de Mestrado em Ciências Criminais da Pucrs. Publicou, entre outros, Agressividade: uma leitura biopsicossocial (Juruá, 2001) e foi co-organizador de Fenomenologia da violência (Juruá, 1999). Contato com o autor: ggauer@terra.com.br. 
mais cresce, ficando abaixo somente dos acidentes de trânsito como causa de mortes no trabalho (Niehoff 1999).

Ainda que não tenhamos tanta disponibilidade de estudos epidemiológicos aplicados à realidade brasileira, vivemos num mundo cada vez mais globalizado $\mathrm{e}$ podemos supor que, no nosso meio, a problemática não seja muito diferente, tendo com certeza importantes conseqüências sociais, psicológicas e econômicas.

Se desejamos fazer progressos no sentido de reduzir os índices de violência, necessitamos considerar que o comportamento é um processo dinâmico de interação entre a fisiologia e a experiência. Se uma entidade merece uma atenção especial no debate a propósito da violência, esta é o cérebro humano, sede da personalidade dos indivíduos.

A personalidade pode ser definida como a soma resultante do temperamento e do caráter de determinado indivíduo. Sendo o temperamento as suas tendências genéticas e constitucionais e o caráter o resultado do aprendizado dentro da estrutura familiar.

O temperamento é a tendência herdada do indivíduo para reagir ao meio de maneira particular e o caráter é o conjunto de formas comportamentais mais elaboradas e determinadas pelas influências ambientais, sociais e culturais as quais o indivíduo usa para adaptar-se ao meio.

Desta forma, o estudo do comportamento humano deve sempre ser analisado dentro de uma perspectiva bio-psico-social, devendo qualquer distúrbio que o indivíduo apresente ser entendido de acordo com suas vivências infantis, suas predisposições constitucionais, a etapa do ciclo vital em que se encontra, a sua situação de doença ou saúde, bem como suas circunstâncias de vida familiar e social. Então, quando pensamos em termos da personalidade de um indivíduo devemos considerá-la em termos da sua relação com o ambiente com o qual ele interage, da influência da sua carga genética e integridade biológica, bem como das suas interações e aprendizado durante a infância. É desta interação de diferentes aspectos que passamos a tratar, iniciando pelos aspectos bio-sociais.

\section{Aspectos bio-sociais e comportamento violento}

A que pese a influência dos fatores inatos, todo o comportamento humano é resultado da interação dele com o ambiente e está constantemente sofrendo novas influências. Neste sentido, sabemos que mesmo o cérebro adulto continua a se 
desenvolver. Estudos demonstram que cérebros de ratos, de todas as idades, respondem aos estímulos que se seguem a sua transferência para um ambiente mais rico e complexo, com uma explosão de novas conexões (Diamond et al. 1987).

O comportamento violento pode ser modificado, mas somente quando os fatores internos e externos que o determinaram forem modificados. Para interromper o círculo vicioso entre os estímulos ambientais nocivos, as percepções negativas e o comportamento desadaptado, o cérebro deve desenvolver uma atitude diferente para com o meio ambiente que o circunda, e o próprio ambiente deve ser diferente. A mudança de um só lado permite que o outro continue a desviar o comportamento em direção ao comportamento violento. Portanto intervenções a nível unicamente neurobiológico, das quais trataremos mais adiante, se empregadas isoladamente, podem ser infrutíferas.

Esta interação ambiente e indivíduo pode ser identificada num estudo de Morgan et al. (1993) Nele ratos foram condicionados ao comportamento de congelamento quando escutavam um som que inicialmente foi associado a um estímulo doloroso. Os ratos dos quais o setor médio do córtex pré-frontal foi removido continuaram a apresentar o comportamento, mesmo quando este não era mais necessário. Porém nos ratos com um córtex intacto foi possível o aprendizado gradual de que o som ameaçador do passado já não devia ser temido no presente.

Desta forma, o controle da agressão requer um sistema nervoso sintonizado com as exigências ambientais, capaz de testar adequadamente a realidade, com um juízo crítico preservado e que não esteja comprometido por doenças de qualquer espécie ou pela interferência de drogas de abuso.

Se desejamos que o cérebro funcione adequadamente na vida adulta, o mesmo deve ser protegido durante a infância e adolescência de fatores que prejudicam seu desenvolvimento, lesem os neurônios ou interfiram com a formação das conexões sinápticas. Para que o eixo hipotálamo-hipófise-adrenal (HPA) responda efetivamente aos estressores vitais os mecanismos de resposta ao estresse devem ser protegidos de estímulos para os quais ainda são imaturos.

A prevenção, que é a intervenção mais precoce e eficaz, inicia-se com os cuidados pré-natais e o bem estar físico e emocional materno. A investigação de abuso de substâncias e violência doméstica deveria ser considerada tão vital como os níveis de tensão arterial. Homens que abusam das mulheres geralmente também o fazem com as crianças. E os danos psicológicos podem ocorrer mesmo que elas não sejam machucadas diretamente. Um estudo demonstrou que crianças tão jo- 
vens como com 2 anos de idade que tinham observado abuso doméstico apresentavam sinais de Transtorno de Estresse Pós-Traumático, tais como alterações no padrão de sono, ansiedade excessiva, indiferença emocional e agressividade (Niehoff 1999).

Se considerarmos que os principais componentes da personalidade são formados nos primeiros anos de vida, e que as vivências infantis desfavoráveis, mesmo que de pequena intensidade, contribuem para problemas na vida adulta, o que podemos esperar quando nos deparamos com vivências tão deletérias como o espancamento, o abuso sexual e a total negligência por parte daqueles de quem a criança depende.

Neste sentido, os estudos demonstram que crianças que foram abusadas e negligenciadas apresentam um risco aumentado de serem presas por um crime violento quando adultas (National Institute of Justice 1996; Windom e Maxfield 1996). Crianças que tinham evidências documentadas de abuso ou negligência tinham o dobro de chances de serem presas quando jovens e uma vez e meia quando adultos. As que tinham sido fisicamente abusadas eram as que tinham maior predisposição para cometerem crimes violentos. Porém as que tinham sofrido só de negligência apresentavam uma incidência apenas um pouco menor (National Center of Child Abuse and Neglect).

Tais dados evidenciam como as vivências infantis negativas podem ser prejudiciais tanto a nível neurofisiológico e para o funcionamento cerebral, como em termos das identificações e da formação da personalidade destes indivíduos. A propósito, cabe lembrar observações tão distintas, porém com um conteúdo semelhante, como o mecanismo de identificação com o agressor descrito por Melanie Klein, ou a observação por estudiosos do comportamento animal de que macacos que são vítimas de agressão tendem a se tornar agressores.

\section{Neurobiologia e comportamento violento}

Ainda que alguns receiem o ressurgimento de ideais eugênicos, ou associem as novas descobertas com as teorias Lombrosianas, é impossível negar que os maiores avanços científicos das últimas décadas se deram na área da biologia. E isto é especialmente verdadeiro quando se trata de psiquiatria biológica. Ainda que o comportamento violento, em especial a agressão impulsiva dirigida a si próprio e aos outros, seja especialmente característico de certos transtornos psiquiátricos, como o transtorno de personalidade borderline (TPB), o anti-social e os transtor- 
nos do humor, ela ocorre em todas as categorias diagnósticas (Woo-Ming e Siever 1998). Sabe-se que alterações biológicas como lesões em estruturas anatômicas podem contribuir para um comportamento violento. Apenas a título de exemplo, cabe citar que cerca de $70 \%$ dos pacientes com dano cerebral por trauma contuso exibem irritabilidade e agressão. Além disto, muitos pacientes com história de raiva descontrolada sofreram trauma encefálico, e a ocorrência de lesão cerebral é significativamente mais comum em homens que espancam suas companheiras do que em homens não violentos (Rosenbaum et al. 1994). Porém em termos de comportamento violento as descobertas mais recentes tratam especialmente das questões do comportamento agressivo impulsivo e as alterações nos neurotransmissores, hormônios e os fatores genéticos envolvidos, conforme passamos a descrever.

\section{Alterações em neurotransmissores}

Inúmeros são os estudos conduzidos com 1) humanos sadios, voluntários em procedimentos experimentais sobre agressividade, 2) humanos com diferentes transtornos psiquiátricos, ou 3) modelos pré-clínicos que aplicam manifestações inatas ou experimentalmente induzidas em primatas ou outros mamíferos, realizados com o intuito de desvendar a participação de um neurotransmissor ou um grupo de substâncias endógenas nas manifestações de agressividade. A vantagem evidente desta descoberta se relaciona à possível prevenção destas alterações, nos indivíduos propensos, e ao tratamento clínico, farmacológico ou cirúrgico, nos indivíduos com alterações comportamentais irreversíveis e/ou importantes.

Esses estudos evidenciam a participação principal de serotonina e noradrenalina, e secundária de outros neurotransmissores com funções inibitórias, sobre o funcionamento de neurônios, como a dopamina e o ácido gama aminobutírico (GABA). Mais recentemente, tem-se tentado verificar a interação dos vários neurotransmissores entre si e com outras substâncias, como hormônios ou agentes com funções de neuromodulação.

\section{Serotonina}

A relação entre neurotransmissores e agressividade é uma das áreas mais intensamente estudadas na psiquiatria biológica. Burrowes et al. (1988), ao citarem um estudo conduzido em 1976 por Asberg et al., um dos primeiros estudos em humanos associando a serotonina (5-HT) à agressividade, relataram haver baixas concentrações do principal metabólito da serotonina, o ácido 5-hidroxiindolacético (5-HIAA), no líquido cefalorraquidiano (LCR) de indivíduos com tentativas de 
suicídio violentas, quando comparados com não-suicidas. Se entendermos que o suicídio é uma forma de auto-agressão, então, tais evidências podem ter aplicabilidade em trabalhos sobre a agressividade e a violência. Posteriormente, Linnoila et al (1983) relataram concentração reduzida de 5-HIAA no LCR em delinqüentes impulsivos violentos e incendiários impulsivos, quando comparados a delinqüentes com violência premeditada, sugerindo que estas condutas agressivas impulsivas estão, especificamente, correlacionadas com uma reduzida função central de 5-HT nestes indivíduos (Cherkasky e Hollander 1997).

Apesar de Joseph S. Alper (1995) questionar os estudos descritos acima, afirmando que ainda não foi encontrada uma relação causal entre as baixas concentrações de 5-HIAA no LCR e comportamento criminoso ou violento bem definido, existem muitas pesquisas realizadas nos últimos 25 anos que sugeriram a correlação entre o comportamento criminoso e as baixas concentrações de 5-HIAA. É possível que estudos posteriores aos iniciais, empregando uma metodologia mais moderna que os anteriores, não tenham confirmado tais resultados, porque o comportamento caracteristicamente associado a baixas concentrações de 5-HIAA varia entre depressão, comportamento agressivo impulsivo e comportamento agressivo geral. Deste modo, torna-se difícil saber se as baixas concentrações de 5HIAA determinam um comportamento anormal ou, ao contrário, um comportamento anormal determina respostas fisiológicas no organismo que levam a uma diminuição de 5-HIAA. É possível que um terceiro fator Bbiológico, psicológico ou ambientalB seja a causa de ambos (comportamento desviante e baixas concentrações de 5-HIAA) (Van Praag 1991).

Estudos farmacológicos examinam a resposta neuroendócrina à administração de um agente que atua num sistema neurotransmissor específico. Os resultados na utilização de tal método trazem como vantagem a avaliação do funcionamento dinâmico dos sistemas de neurotransmissão em áreas cerebrais específicas. Cherek e Lane (1999) realizaram um estudo utilizando a d, 1-fenfluramina (substância que aumenta a liberação e bloqueia a recaptação da 5-HT no neurônio pré-sináptico, tornando-a mais disponível na fenda sináptica) em 10 indivíduos com história de distúrbio de conduta e comportamento criminoso. A administração de d, 1fenfluramina, nas doses de 0,2, 0,4 e 0,8mg/kg, produziram respostas agressivas e impulsivas progressivamente menores, de forma dose-dependente. Baseados nestas evidências, os autores concluíram que o aumento da serotonina pela d, 1fenfluramina é um possível mecanismo determinante de redução da agressão e impulsividade (Alper 1995). Em outro estudo utilizando fenfluramina, notou-se 
que o aumento na 5-HT central resulta num transitório, mas acentuado, aumento na prolactina sérica. Foi observado que macacos com resposta serotonérgica embotada de prolactina à fenfluramina, apresentavam gestos mais agressivos em conseqüência da ameaça de um ser humano do que os com prolactina elevada (Kyes et al. 1995).

Outras medidas da função central do sistema 5-HT se encontram anormais em pacientes com história de comportamento agressivo impulsivo. Por exemplo, a ligação da $3 \mathrm{H}$-imipramina, uma medida do funcionamento pré-sináptico da 5-HT, encontra-se reduzida no cérebro de vítimas de suicídio violento (Cherek e Lane 1999), o que está de acordo com as observações de captação plaquetária de 5-HT inversamente correlacionada com medidas de impulsividade, em pacientes com agressão episódica (Stanley et al. 1982), e números reduzidos de sítios transportadores plaquetários de 5-HT, associados com história de comportamento agressivo em pacientes com transtorno de personalidade (Sarne et al. 1995). Por outro lado, fica difícil explicar por que um estudo demonstrou que delinqüentes violentos apresentam maior ligação de imipramina plaquetária do que os delinqüentes não-violentos, pacientes esquizofrênicos ou voluntários normais (Brown et al. 1989). Certamente, esta observação dá margem a futuros estudos sobre a evolução temporal de alterações neuroquímicas serotonérgicas, gerando adaptações de vias neuronais, associados a distúrbios comportamentais.

Mais evidências sobre o papel desempenhado pela serotonina na regulação da conduta agressiva impulsiva são provenientes de estudos demonstrando que drogas inibidoras específicas da recaptação da 5-HT podem ser eficazes na diminuição de tal conduta. Um estudo duplo-cego, realizado com 21 pacientes com TPB, demonstrou uma redução estatisticamente significativa no nível da raiva avaliada clinicamente entre aqueles pacientes que receberam fluoxetina durante 13 semanas, independente de modificações na depressão (Salzman et al. 1989). O tratamento com um inibidor seletivo de recaptação da serotonina, o citalopram, avaliado através de estudo duplo-cego, determinou uma redução da agressividade em pacientes esquizofrênicos cronicamente violentos (Vartiainen et al. 1995). A sertralina também se demonstrou efetiva para diminuir a agressão impulsiva e irritabilidade em paciente não-deprimidos com uma variedade de distúrbios de personalidade (Kavoussi et al. 1994).

Outros estudos encontraram uma relação inversa entre índices elevados de função central do sistema serotonérgico e a diminuição da agressão impulsiva em pacientes usando outros agentes agonistas diretos dos receptores de serotonina, a 
m-clorofenilpiperazina (Hollander et al. 1994), e os agonistas dos receptores 5$\mathrm{HT}_{1 \mathrm{~A}}$, a buspirona (Coccaro et al 1990; Ratey et al. 1991) e a ipsapirona (Coccaro et al. 1995).

A manipulação dietética do 1-triptofano, aminoácido precursor da síntese de serotonina, também tem apoiado a hipótese do papel da serotonina na regulação da agressão. Quando indivíduos são submetidos a dietas pobres em 1-triptofano, fica evidenciada a existência de uma correlação entre conduta agressiva e as concentrações plasmáticas diminuídas deste aminoácido, ao passo que se observa alteração na conduta agressiva nos indivíduos que recebem dieta rica em triptofano (Bjork et al. 1999).

A violência tem a tendência a um desfecho de desespero e suicídio. Assassinos escolhem eles próprios como sua última vítima com uma freqüência setecentas vezes maior que os indivíduos sem problemas legais. Uma pesquisa numa prisão de Detróit revelou que 60\% dos suicídios ocorreu na pequena população de presos cumprindo pena por homicídio. Um outro estudo demonstrou que níveis reduzidos de 5-HT e 5-HIAA não estava apenas correlacionado a tentativas prévias de suicido, mas também a uma história de vida marcada por explosões de agressividade contra os outros (Niehoff 1999; Brown et al. 1979; Brown et al. 1982).

Portanto, apesar de algumas contradições, a maioria dos estudos com humanos e com diferentes espécies animais aponta a deficiência da serotonina, por fatores dietéticos ou endógenos, como importante na expressão de comportamentos agressivos impulsivos. Sendo que as características de personalidade destes indivíduos poderiam ser descritas como uma tendência a agir impulsivamente, com dificuldade para parar e pensar. Com freqüência eles admitem e sentem-se envergonhados por terem agido erroneamente. Porém só conseguem se dar conta disto posteriormente.

\section{Catecolaminas e outros neurotransmissores}

Existem, também, evidências que apontam no sentido de uma inter-relação entre os sistemas noradrenérgicos e dopaminérgicos e a conduta agressiva.

Estudos em animais sustentam a hipótese de que a norepinefrina (NE) tem um efeito direto na agressão e que o aumento da atividade dopaminérgica cerebral cria condições para que os animais estejam mais propensos a responder de forma impulsiva e agressivamente a estímulos ambientais (Blackburn et al. 1992). No entanto, a NE pode modular a agressão impulsiva mediada serotonergicamente. A 
diminuição da NE, por exemplo, pode levar à depressão, ao suicídio e à agressão auto-dirigida; por outro lado, seu aumento pode levar à heteroagressão e à irritabilidade (Cherkasky e Hollander 1997). Foi constatado, também, que os níveis de NE eram significativamente maiores em indivíduos com agressividade basal aumentada, bem como os níveis de cortisol e hormônio do crescimento, na medida em que estes hormônios são estimulados pela NE. Esta observação também pode ser válida para a correlação entre o grau de agressividade e o aumento da freqüência cardíaca e da pressão arterial dependentes da NE após o estímulo. As respostas do hormônio do crescimento ao agonista alfa-2 adrenérgico, a clonidina, são maiores em pacientes com transtorno de personalidade do que em depressivos em remissão ou controles. Estas repostas correlacionavam-se positivamente a medidas auto-relatadas de irritabilidade ao longo da vida, tanto em pacientes com transtorno de personalidade, como em controles normais (id. ibid.; Gerra et al. 1997).

Raine e Buchsbaum (1996) citam um estudo realizado por Brown et al. (1988), onde foram feitas investigações com militares hospitalizados, portadores de distúrbio de personalidade, nos quais examinaram as concentrações do principal metabólico da NE, o 3-metil-4-hidroxifenilglicol (MHPG), e observaram uma correlação positiva entre níveis mais altos de MHPG no LCR com uma história de comportamento agressivo. Consistente com estes achados, houve relatos de que o antagonista b-adrenérgico (propranolol) pode ser eficiente no tratamento da conduta agressiva episódica (Mann 1995).

Brain (1994), citando uma revisão feita por Miczeck et al. em 1990 sobre a neuroquímica e o manejo fármaco-terapêutico da violência, refere que a NE cerebral sofre grandes variações antes, durante e depois de diferentes tipos de comportamento agressivo e depressivo, e que estas mudanças localizam-se em regiões cerebrais específicas, que parecem funcionar em oposição. Sugeriu, também, que a dopamina cerebral desempenha particular importância nos aspectos gratificantes da violência e nos mecanismos neurais que iniciam, executam e encerram os padrões agressivos de comportamento. Por outro lado, o complexo receptor GABAbenzodiazepínicos está implicado, de maneira complexa, no comportamento agressivo e violento. Este neurotransmissor inibitório, o GABA, também é associado à impulsividade e à agressividade. Estudos experimentais, citados por Burrowes et al. (1998), evidenciam que ratos muito agressivos têm níveis diminuídos de GABA no Sistema Nervoso Central, e o tratamento com ácido valpróico, um agente que aumenta a atividade cerebral do GABA, reduz esta agressividade. 


\section{Esteróides sexuais e outros hormônios}

Algumas pesquisas em seres humanos, bem como estudos em animais, têm sugerido que os andrógenos podem ter um papel na agressão. Entretanto, a natureza desta modulação não é clara. Estudo conduzido por Bonson et al. (1994) sugere que, quando ratos que se tornaram dominantes após administração de testosterona, receberam agonistas da serotonina, apresentaram uma diminuição dose-dependente da agressividade. Tal informação sugere que os sistemas serotonérgicos podem interagir com esteróides sexuais para regular o comportamento agressivo. Em humanos, baixa concentração liqüórica de 5-HIAA foi associada primariamente à impulsividade geral, enquanto alta concentração de testosterona no LCR foi associada com agressividade ou violência interpessoal (Virkkunen et al. 1994). Mesmo sem compreender como a testosterona influencia o comportamento agressivo, os estudos são claros em apontar sua importância em processos fisiopatológicos. Delinqüentes violentos parecem ter níveis mais altos de testosterona do que aqueles que cometeram crimes não-violentos (roubo, furto, tráfico de drogas) e os com altos níveis de testosterona também têm uma conduta mais agressiva na prisão (Bernhardt et al. 1998). Em delinqüentes violentos alcoolistas, a alta concentração de testosterona livre no LCR está associada ao aumento da agressividade (Scerbo e Kolko 1994; Virkkunen e Narvanen 1987).

Mesmo em indivíduos normais, há relação entre diferentes níveis de testosterona e o desenvolvimento de conduta agressiva. Homens física e sociologicamente sadios apresentam agressividade não-estimulada maior se há testosterona basal aumentada, mesmo que dentro de limites normais, do que nos sujeitos com níveis basais mais baixos (Moss et al. 1986).

Embora os níveis de testosterona possam estar elevados em delinqüentes agressivos, o uso de antiandrógenos tem tido benefício limitado, talvez porque hajam outras influências hormonais que intervêm no desenvolvimento da agressividade. Foi encontrada uma correlação positiva entre concentrações plasmáticas de prolactina e o desenvolvimento da agressividade (Bonson et al. 1994).

No entanto, o acetato de medroxiprogesterona e o acetato de ciproterona parecem diminuir tanto a atividade como o impulso sexual desviante e não-desviante em homens com parafilias, e esta melhora comportamental está associada aos níveis de testosterona (Kravitz et al. 1996).

Há a possibilidade de outras alterações hormonais estarem servindo como marcadores de maior ou menor agressividade entre os indivíduos. 
A atividade da tireóide parece ter uma correlação com a conduta agressiva. Foi descoberto que uma atividade excessiva no funcionamento da tireóide está relacionada a uma diminuição do sistema simpático em grupos de indivíduos do sexo masculino com diferentes formas de desvio psicossocial (Whybrow e Prange Jr. 1981; Moss et al. 1986).

Alm et al. (1996), num estudo realizado com jovens delinqüentes primários, observaram que os níveis de triiodotironina (T3) eram significativamente associados com a criminalidade, mas não com traços de personalidade anti-social. Os níveis do hormônio estimulante da tireóide (TSH) não foram relacionados a nenhuma das variáveis anteriores. Os jovens delinqüentes que manifestavam comportamento criminoso persistente tinham um nível de T3 mais elevado que os delinqüentes juvenis sem manifestações de criminalidade quando adultos, bem como de não-criminosos. Jovens delinqüentes com níveis de T3 acima do nível médio tinham registros de criminalidade 3,8 vezes mais freqüentes do que os jovens delinqüentes com nível T3 abaixo do nível médio encontrado no grupo controle. Em combatentes veteranos do Vietnã, um aumento similar nos níveis de T3 foi detectado entre 20 e 30 anos após os eventos traumáticos. Os níveis de T3 parecem diferir entre sujeitos com comportamento desviante/criminoso e sujeitos com comportamento social normal, assim como entre sujeitos expostos a eventos psicotraumáticos extremamente estressantes e sujeitos que não experimentaram tais eventos (Mason et al. 1994).

Stalenhein et al. (1998) encontraram níveis elevados de T3 relacionados ao alcoolismo, criminalidade e distúrbio anti-social. Este estudo demonstrou uma diminuição nos níveis séricos de tiroxina livre (FT4) nos mesmos indivíduos que apresentaram altos níveis de T3 associados ao comportamento agressivo. Tais resultados indicam, portanto, uma estreita relação entre T3 e FT4 com abuso de álcool e comportamento anti-social, necessitando enfatizar-se a importância de mais estudos sobre o T3 como marcador biológico para abuso, desvio social e comportamento violento repetido.

\section{Fatores genéticos}

Sabemos que muitos estudos sugerem uma relação entre fatores genéticos e conduta anti-social, bem como a associação entre a baixa atividade 5-HT cerebral com a impulsividade e agressão. 
Estudos cromossômicos têm considerado a influência de anormalidades cromossômicas na agressão, particularmente na síndrome XYY (Wong et al. 1994). Contudo, a ligação entre XYY e violência não tem sido confirmada. Outros estudos sugeriram que os homens XYY são mais impulsivos para tomar decisões, têm temperamento mais forte e, muitas vezes, estão no limite inferior da inteligência normal. Provavelmente não sejam primariamente agressivos; entretanto, como têm características mais impulsivas, estas podem conduzir a um comportamento agressivo (Nielsen et al. 1973; Zeuthen et al. 1975). Estudos realizados com gêmeos buscaram uma comparação da conduta criminosa dos gêmeos univitelinos (monozigóticos) com a dos gêmeos bivitelinos (dizigóticos). $\mathrm{O}$ argumento utilizado é de que se a estrutura de um dos gêmeos univitelinos fosse tendente ao crime, a do outro também seria, baseado na herança genética comum de ambos. Assim, as investigações são dirigidas no sentido de demonstrar quantas vezes a criminalidade de um dos gêmeos é acompanhada pelo outro, medindo-se, assim, a influência dos fatores hereditários. Pesquisas realizadas em vários países apontaram uma concordância dos gêmeos monozigóticos para o crime Batingindo 67,3\% dos casos estudados $\mathbf{B}$ e uma discordância (somente um dos gêmeos delinqüentes) de 32,7\%. Em relação aos gêmeos dizigóticos, a situação foi inversa: concordância em 33\% e discordância em 67\% (Souza 1999: 121-31).

Estudos de adoção têm sugerido que a herança de fatores genéticos parece exercer um efeito na expressão do comportamento criminoso. Num estudo dinamarquês de adoção, verificou-se que os filhos homens adotados tinham um risco maior de serem condenados se seus pais biológicos tivessem uma ou mais condenações. Além disto, outras pesquisas também apontam na direção de uma relação entre reincidência de crimes de pais biológicos e seus filhos homens que foram adotados. Condenações criminais e, particularmente, taxas de reincidência entre pais biológicos e seus filhos que foram adotados, apresentam um apoio ao modelo genético de comportamento criminoso (Tehrani et al. 1998). Investigações recentes, baseadas em técnicas de PCR Ba “polymerase chain reaction”'B vêm identificando implicações em certos tipos de condutas anti-sociais, suicidas e com relação ao alcoolismo, pela variação do gene TPH, da triptofano hidroxilase, mapeado no braço menor do cromossoma 11 (Souza 1999: 121-31). Esta enzima controla a síntese da serotonina, a partir o triptofano e pode ser responsável por variações nas concentrações de serotonina cerebral. Estão sendo associadas a este gene os impulsos agressivos e comportamentos violentos decorridos, principalmente, da alteração da concentração de 5-HIAA no LCR (Tehrani et al. 1998), como já revisado. 
Por outro lado, a conduta agressiva, como visto anteriormente, tem sido relacionada com alterações nas catecolaminas. Todo o processo de síntese e de catabolismo das catecolaminas está relacionado a enzimas, cujas atividades são controladas pelo código genético.

Uma enzima que está presente nos neurônios, a Catecol-o-metiltransferase (COMT), inativa as catecolaminas (Pucilowski et al. 1986; Ratey e Gordon 1993). Um polimorfismo comum no grau da COMT no códon 158 resulta numa substituição da valina pela metionina, e está associada a diferenças de 3 a 4 vezes na atividade da COMT entre indivíduos homozigóticos. Já os indivíduos heterozigóticos apresentam níveis intermediários de atividade (Pucilowski et al. 1986; Weinshilboum e Raymond 1977). O alelo de baixa atividade da COMT parece aumentar a tendência à conduta agressiva, enquanto o alelo de alta atividade pode ter um efeito protetor (Stous et al. 1997; Lachman et al. 1998). Também há uma associação entre o genótipo da COMT e agressividade em indivíduos esquizofrênicos.

Outra enzima envolvida na metabolização da serotonina, dopamina e noradrenalina é a monoaminooxidase (MAO). Estudos genéticos e metabólicos foram realizados numa família holandesa, onde os homens apresentavam um tipo de comportamento que incluía agressividade impulsiva (Brunner et al. 1993). Os homens desta família apresentavam uma mutação genética pontual na MAO A associada ao protótipo comportamental, que inclui regulação perturbada da agressividade impulsiva. O gene A para MAO A é a primeira demonstração de um gene alterado, especificamente implicado no comportamento criminoso agressivo. Como a MAO A também está envolvida no metabolismo serotonérgico, é possível sugerir que a mutação gênica que resulta em deficiência de MAO A está relacionada a baixas concentrações de 5BHIAA encontradas em associação com comportamento criminoso (Oreland e Hallman 1989).

De aplicação mais imediata, a MAO plaquetária é um marcador biológico para a vulnerabilidade à psicopatologia (Alm et al. 1994). É provável que tal vulnerabilidade esteja relacionada a traços de personalidade impulsiva, uma vez que a atividade da MAO plaquetária baixa está correlacionada à busca de sensações, à impulsividade e a evitações da monotonia em homens e mulheres. A atividade plaquetária média nos indivíduos com criminalidade anterior aos 15 anos era significativamente mais baixa que nos ex-delinqüentes sem criminalidade após os 15 anos. Desta maneira, indivíduos com atividade MAO plaquetária baixa apresentam um risco maior de comportamento criminoso precoce e continuado (Coccaro et al. 1998). 
Portanto, a diminuição da atividade das enzimas metabolizadoras das catecolaminas parece estar mais relacionada às condutas agressivas, talvez devido à possibilidade geneticamente determinada de haver níveis cerebrais aumentados de noradrenalina.

Para finalizar, cabe ainda citar um estudo familiar demonstrando que familiares de primeiro grau de pacientes com TPB apresentavam uma prevalência significativamente aumentada de comportamento impulsivo e agressivo, bem como labilidade afetiva, quando comparado com familiares de pacientes esquizofrênicos ou com outros transtornos de personalidade (Silverman e Pinkham 1991).

\section{Avanços futuros na área biológica}

Recentemente, um neuropeptídeo, a arginina vasopressina (AVP), tem sido implicado na agressão. Em humanos, examinou-se a relação entre a AVP no LCR, os índices de agressão e a função serotonérgica em indivíduos com transtorno de personalidade segundo a DSM-IV (Stribley e Carter 1999), concluindo que a AVP central pode aumentar o comportamento agressivo, nestes indivíduos, enquanto a serotonina pode inibir tal comportamento. Além disto, há a possibilidade de a AVP central, interagindo com a serotonina, influenciar o comportamento humano agressivo. Por outro lado, a AVP pode influenciar, também, o comportamento humano por mecanismo independente da serotonina central em sujeitos com transtorno de personalidade.

Estudos em roedores indicam que injeções intraventriculares de AVP podem aumentar significativamente a agressão entre os machos, sugerindo um papel para AVP na expressão da agressão. Neste estudo, foi demonstrado que uma exposição pós-natal precoce à AVP pode ter um efeito permanente na tendência para demonstrar a agressão. Os ratos fêmeas, além de demonstrarem menos a agressão, são menos responsivas à AVP exógena; entretanto, a capacidade do antagonista do receptor AVP V (1a) para bloquear a agressão em fêmeas tem implicado a AVP no desenvolvimento de conduta agressiva nas mesmas (Ferris e Delville 1994). A 5HT pode antagonizar a atividade da AVP no SNC. Por exemplo, micro-injeções de 5-HT no hipotálamo anterior inibem a agressão induzida por AVP, enquanto o bloqueio da recaptação de serotonina por injeção intraperitoneal de fluoxetina diminui a agressão ofensiva induzida por AVP. Portanto, é possível que os sistemas serotonérgicos interajam com a AVP para modular a agressão ofensiva (Nelson et al. 1995). 
Ressalta-se que são descritas alterações adicionais interessantes sobre a modulação da agressão e que poderão, num futuro próximo, ser demonstradas seu valor diagnóstico ou terapêutico. Nesta categoria foi observado que ratos com perturbação da NO sintetase neuronal (sNOS) tinham um grande aumento no comportamento agressivo e um comportamento sexual excessivamente inapropriado (Golomb 1998).

O óxido nítrico (NO) é um neurotransmissor encontrado em altas densidades nas regiões cerebrais que regulam a emoção.

Estudos de observação, na clínica, demonstraram um aumento de comportamento violento em pessoas com baixos níveis de colesterol. Pesquisas em humanos e animais, recebendo dietas pobres em colesterol, indicam que níveis baixos, ou nos limites inferiores de colesterol, podem reduzir a atividade serotonérgica central, a qual, por sua vez, está relacionada ao comportamento violento (Bernhardt et al. 1998).

\section{Comentários finais}

Conforme mencionado previamente, as causas da conduta agressiva são influenciadas por vários fatores biológicos complexos. Estes sistemas biológicos funcionam de forma integrada, resultando, assim, na expressão do comportamento agressivo impulsivo. Novas tecnologias têm demonstrado estruturas cerebrais envolvidas na mediação da agressão. De acordo com o avanço de tais técnicas, poderá ser possível o descobrimento de um retrato mais completo destas estruturas e do modo como influenciam a agressão. Porém deve-se ter em mente que não será apenas o excesso ou a falta de apenas uma, ou mesmo várias, substância no SNC que irá responder a complexa questão do comportamento violento. Assim como a neurotransmissão é um diálogo entre as células do SNC, o comportamento é um diálogo entre o passado e o presente e entre a experiência e a fisiologia.

Desta forma, salientamos que apesar de termos privilegiado aqui a discussão dos aspectos biológicos relacionados ao comportamento violento, como as alterações nos neurotransmissores, nos hormônios e as influências genéticas, já que são estas áreas onde o conhecimento científico mais tem avançado nas últimas décadas, na realidade, como foi dito no início deste trabalho, temos que pensar na personalidade do ser humano de um ponto de vista bio-psico-social. Onde fatores biológicos, inatos ou não, se retroalimentam com os estímulos ambientais. Para entendermos melhor este processo podemos fazer uma analogia com outro animal 
social que é o elefante. Este durante a infância se envolve em pequenas lutas com seus iguais para testar sua força. Desta maneira ele tem uma idéia se pode ou não se envolver em lutas por disputa de território na idade adulta. Uma falha, de qualquer natureza, neste aprendizado pode fazer um elefante superestimar suas capacidades e acabar sendo facilmente morto por um rival muito mais forte. Enquanto outro elefante, mesmo sendo mais frágil do que os outros membros com os quais convive, mas com um aprendizado adequado, pode vir a ter sua prole e sobreviver evitando os conflitos dos quais já sabe sairá perdedor.

Da mesma forma uma interação entre experiências precoces desfavoráveis, diminuição dos níveis de serotonina cerebral e alterações neuroendócrinas podem determinar um comportamento humano que resulte num prejuízo para o próprio indivíduo e para a sociedade.

Só recentemente os complexos mecanismos que são responsáveis pela nossa atividade cerebral começaram a ser desvendados e, neste sentido, estamos apenas dando os primeiros passos. Verifica-se que muito ainda precisa ser estudado e pesquisado, até que se chegue a conclusões mais definitivas que auxiliem, de forma técnica e consistente, na prevenção e no tratamento do comportamento agressivo de forma a influenciar efetivamente a vida social do ser humano.

\section{Bibliografia citada}

Alm, P. O. et al. (1996). Criminality and psychopathy as related to thyroid activity in former juvenile delinquents. Acta Psychiatrica Scandinavica, v. 94, n. 2, p. 112-117.

Alm, P. O. et al. (1994). Criminality and platelet monoamine oxidase activity in former juvenile delinquents as adults. Acta Psychiatrica Scandinavica, v. 89, n. 1, p. 41-45.

Alper, J. S. (1995). Biological influences on criminal behaviour: how good is the evidence: $B M J U$, v. 310, n. 6975, p. 272-273.

Bernhardt, P. C. et al. (1998). Testosterone changes during vicarious experiences of winning and losing among fans at sporting events. Physiology and Behavior, v. 65 , n. 1 , p. 59-62.

Bjork, J. M. et al. (1999). The effects of tryptophan depletion and loading on laboratory aggression in men: time course and a food-restricted control. Psychopharmacology, Berlin, v. 142, n. 1, p. 24-30. 
Blackburn, J. R. et al. (1992). Dopamine functions in appetitive and defensive behaviours. Progress in Neurobiology, v. 39, n. 3, p. 247-279.

Bland r, Orn H. (1986). Family violence and psychiatric disorder. Can. J. Psychiatry, 31:129-137.

Bonson, K. R. et al. (1994). Serotonergic control of androgen-induced dominance. Pharmacology, Biochemistry, and Behavior, v. 49, n. 2, p. 313-322.

Brain, P. F. (1994). Biological-Physiological. In: Hersen, M. et al. (org.). Handbook of aggressive and destructive behavior in psychiatric patients. New York: Plenum Press, p. 3-16.

Brown, G. L. et al. (1979). Aggression in humans correlates with cerebrospinal fluid amine metabolites. Psychiatry Research, v. 1, p. 131-139.

Brown, G. L. et al. (1982). Aggression, suicide, and serotonin-relationships to CSF amine metabolites. American Journal of Psychiatry, v. 139, p. 741-746.

Brown, C. S. et al. (1989). Blood platelet uptake of serotonin in episodic aggression. Psychiatry Research, v. 27, n. 1, p. 5-12.

Brunner, H. G. et al. (1993). Abnormal behavior associated with a point mutation in the structural gene for monoamine oxidase A. Science, v. 262, n. 5133, p. 578-580.

Burrowes, K. L. et al. (1988). Research on the biologic aspects of violence. Psychiatric Clinics of North America, v. 11, n. 4, p.499-509.

Cherek, D. R., Lane, S. D. (1999). Effects of d,l-fenfluramine on aggressive and impulsive responding in adult males with a history of conduct disorder. Psychopharmacology, Berlin, v. 146, n. 4, p. 473-481.

Cherkasky, S., Hollander, E. (1997). Neuropsychiatric aspects of impulsivity and aggression. In: Yudoofsky, S. C., Males, R. E. (org.). The American Psychiatric Press textbook of neuropsychiatry. 3. ed. Washington DC: American Psychiatric Press, p. 485-499.

Coccaro E. F. et al. (1998). Cerebrospinal fluid vasopressin levels: correlates with aggression and serotonin function in personality-disordered subjects. Archives of General Psychiatry, v. 55, n. 8, p. 708-714.

Coccaro, E. F. et al. (1995). Physiological responses to d-fenfluramine and ipsapirone challenge correlate with indices of aggression in males with personality disorder. International Clinical Psychopharmacology, v. 10, n. 3, p. 177-179.

Coccaro, E. F., et al. (1990). Buspirone challenge: preliminary evidence for a role for central 5-HT1a receptor function in impulsive aggressive behavior in humans. 
Psychopharmacology Bulletin, v. 26, n. 3, p. 393-405.

Diamond, M. C. et al. (1987). Rat cortical morphology following crowded-enriched living conditions. Experimental Neurology, v. 96, p. 241-247.

Federal Bureau of Investigation (1996). Crime in the United States 1996. Washington D.C., Department of Justice.

Ferris, C. F., Delville, Y. (1994). Vasopressin and serotonin interactions in the control of agonistic behavior. Psychoneuroendocrinology, v. 19, n. 5-7, p. 593601.

Gerra, G. et al. (1997). Neurotransmitter-neuroendocrine responses to experimentally induced aggression in humans: influence of personality variable. Psychiatry Research, v. 66, n. 1, p. 33-43.

Golomb, B. A. (1998). Cholesterol and violence: is there a connection? Annals of Internal Medicine, v. 128, n. 6, p. 478-487.

Hollander, E. et al. (1994). Serotonergic sensitivity in borderline personality disorder: preliminary findings. American Journal of Psychiatry, v. 151, n. 2, p. 277-280.

Kavoussi, R. J. et al. (1994). An open trial of sertraline in personality disordered patients with impulsive aggression. Journal of Clinical Psychiatry, v. 55, n. 4, p. 137-141.

Kravitz, H. M. et al. (1996). Medroxyprogesterone and paraphiles: do testosterone levels matter? Bulletin of American Academy of Psychiatry and the Law, v. 24, n. 1, p. 73-83.

Kyes, R. C. et al. (1995). Aggression and brain serotonergic responsivity: response to slides in male macaques. Physiology and Behavior, v. 57, n. 2, p. 205-208.

Lachman, H. M. et al. (1998). Association between catechol O-methyltransferase genotype and violence in schizophrenia and schizoaffective disorder. American Journal of Psychiatry, v. 155, n. 6, p. 835-837.

Linnoila, M. et al. (1983). Low cerebrospinal fluid 5-hydroxyindoleacetic acid concentration differentiates impulsive from nonimpulsive violent behavior. Life Sciences, v. 33, n. 26, p. 2609-2614.

Mann, J. J. (1995). Violence and aggresion. In: Bloom, F. E., Kupfer, D. J. (org.). Psychopharmacology: the fourth generation of progress. New York : Raven Press, p.1919-1928.

Mason, J. et al. (1994). Elevation of serum free triiodothyronine, total triiodothyronine, thyroxine-binding globulin, and total thyroxine levels in combat-related posttraumatic stress disorder. Archives of General Psychiatry, 
v. 51, n. 8 , p. 629-641.

Morgan, M. A. et al. (1993). Extinction of emotional learning: Contribution of prefrontal cortex. Neuroscience Letters, v. 163, p. 109-113.

Moss, H. B. et al. (1986). Enhanced thyrotropin response to thyrotropin releasing hormone in boys at risk for development of alcoholism: preliminary findings. Archives of General Psychiatry, v. 43, n. 12, p. 1137-1142.

National Center of Child Abuse and Neglect (s. d.). National child abuse and neglect statistical fact sheet (on-line), National Clearinghouse on Child Abuse and Neglect Information: www.nccanch@calib.com.

National Institute of Justice (1996). The cycle of violence revisited (on-line report). National Criminal Justice Reference Service, Feb. 1996. www.ncjrs.org.

Nelson, R. J. et al. (1995). Behavioural abnormalities in male mice lacking neuronal nitric oxide synthase. Nature, v. 378, n. 6555, p. 383-386.

Niehoff, D. (1999) The Biology of Violence. New York: The Free Press.

Nielsen, J. et al. (1973). A psychiatric-psychological study of patients with the XYY syndrome found outside of institutions. Acta Psychiatrica Scandinavica, v. 49, n. 2, p. 159-168.

Oreland, L., Hallman, J. (1989). Blood platelets as a peripheral marker for the central serotonin sys tem. Nordisk Psykiatrisk Tidsskrift, v. 20, p. 43-51.

Pucilowski, O. et al. (1986). Effect of 6-OHDA injected into the locus coeruleus on apomorphine-induced aggression. Pharmacology, Biochemistry, and Behavior, v. 24, n. 3, p. 773-775.

Raine, A. e Buchsbaum, M. S. (1996). Violence, brain imaging and neuropsychology. In: Stoff, D. M. e Cairns, R. B. (org.). Aggresssion and violence: genetic, neurobiological and biosocial perspectives. Mahwah: Lawrence Erlbaum Associales, p. 195-217.

Ratey, J. et al. (1991). Buspirone treatment of aggression and anxiety in mentally retarded patients: a multiple-baseline, placebo lead-in study. Journal of Clinical Psychiatry, v. 52, n. 4, p. 159-162.

Ratey, J. J. e Gordon, A. (1993). The psychopharmacology of aggression: toward a new day. Psychopharmacology Bulletin, v. 29, n. 1, p. 65-73.

Rosenbaum, A. et al. (1994). Head injury in partner-abusive men. Journal of Consulting and Clinical Psychology, v. 62, n. 6, p. 1187-1193.

Salzman, C. et al. (1995). Effect of fluoxetine on anger in symptomatic volunteers with borderline personality disorder. Journal of Clinical Psychopharmacology, v. 15 , n. 1, p. $23-29$. 
Sarne, Y. et al. (1995). Imipramine binding to blood platelets and aggressive behavior in offenders, schizophrenics and normal volunteers. Neuropsychobiology, v. 31, n. 3, p. 120-124.

Scerbo, A. S., Kolko, D. J. (1994). Salivary testosterone and cortisol in disruptive children: relationship to aggressive, hyperactive, and internalizing behaviors. Journal of the American Academy of Child and Adolescent Psychiatry, v. 33, n. 8 , p. $1174-1184$.

Silverman, J. M.; Pinkham, L. (1991). Affective and impulsive personality disorder traits in the relatives of patients with borderline personality disorders. American Journal of Psychiatry, v. 148, p. 1378-1385.

Souza, P. V. S. (1999). A criminalidade genética. Porto Alegre, 169 fl. Dissertação (Mestrado em Ciências Criminais). Faculdade de Direito, Pucrs.

Stalenheim, E. G.et al. (1998). Serum levels of thyroid hormones as biological markers in a Swedish forensic psychiatric population. Biological Psychiatry, v. 43, n. 10 , p. 755-761.

Stanley, M. et al. (1982). Tritiated imipramine binding sites are decreased in the frontal cortex of suicides. Science, v. 216, n. 4552, p. 1337-1339.

Stribley, J. M., Carter, C. S. (1999). Developmental exposure to vasopressin increases aggression in adult prairie voles. Proceedings of the National Academy of Sciences of the United States of America, v. 96, n. 22, p. 12601-12604.

Strous, R. D. et al. (1997). Analysis of a functional catechol-O-methyltransferase gene polymorphism in schizophrenia: evidence for association with aggressive and antisocial behavior. Psychiatry Research, v. 69, n. 2-3, p. 71-77.

Swanson, J. W. et al. (1990). Violence and psychiatric disorder in the community: Evidence from Epidemiologic Catchment Area surveys. Hosp. Community Psychiatry, v. 17, p. 173-186.

Tehrani, J. A. et al. (1998). Mental illness and criminal violence. Social Psychiatry and Psychiatric Epidemiology, v. 33 Suppl. 1, p. s81-s85.

Van Praag, H. M. (1991). Serotonergic dysfunction and aggression control. Psychlogical Medicine, v. 21, n. 1, p.15-19.

Vartiainen, H. et al. (1995). Citalopram, a selective serotonin reuptake inhibitor, in the treatment of aggression in schizophrenia. Acta Psychiatrica Scandinavica, v. 91, n. 5 , p. $348-351$.

Virkkunen, M. et al. (1994). Personality profiles and state aggressiveness in finnish alcoholic, violent offenders, fire setters, and healthy volunteers. Archives of General Psychiatry, v. 51, n. 1, p. 28-33. 
Virkkunen, M. e Narvanen, S. (1987). Plasma insulin, tryptophan and serotonin levels during the glucose tolerance test among habitually violent and impulsive offenders. Neuropsychobiology, v. 17, n. 1-2, p. 19-23.

Weinshilboum, R. M. e Raymond, F. A. (1977). Inheritance of low erythrocyte catechol-o-methyltransferase activity in man. American Journal of Human Genetics, v. 29, n. 2, p. 125-135.

Whybrow, P. C. e Prange Jr., A. J. (1981). A hypothesis of thiroid B catecholamine receptorinteraction. Archives of General Psychiatry, v. 38, n. 1, p. 106-113.

Windom, C. S. e Maxfield, A. (1996) A prospective examination of risk for violence among abused and neglected children. Annals of the New York Academy of Sciences, v.794, p. 224-237.

Wong, M. T. et al. (1994). Electroencephalography, computed tomography and violence ratings of male patients in a maximum-security mental hospital. Acta Psychiatrica Scandinavica, v. 90, n. 2, p. 97-101.

Woo-Ming, A. M. e Siever, L. J. (1998). Psychopharmacological Treatment of Personality Disorders. In: Nathan, P. E., Gorman, J. M. A Guide to Treatments that Work. New York: Oxford University Press, p.554-567.

Zeuthen, E. et al. (1975). A psychiatric-psychological study of XYY males found in a general male population. Acta Psychiatrica Scandinavica, v. 51, n. 1, p. 318. 
